\title{
The Effect of Serum-factor Induced Resistance to Somatic Antibodies on the Virulence of Haemophilus influenzae Type b
}

\author{
By LORRY G. RUBIN* $\dagger$ AND E. RICHARD MOXON \\ Department of Pediatrics, Eudowood Division of Infectious Diseases, The Johns Hopkins \\ University School of Medicine, Baltimore, Maryland, USA
}

(Received 17 July 1984; revised 15 October 1984)

\begin{abstract}
Studies on the pathogenesis of Haemophilus influenzae $\mathrm{b}$ infection have used bacteria grown in vitro which are relatively serum-sensitive (using serum devoid of anticapsular antibody) compared to organisms taken from infected hosts. We compared the virulence of relatively serum-sensitive and serum-factor induced serum-resistant $\boldsymbol{H}$. influenzae b by inoculating rats with organisms having one or the other phenotype. The serum-resistant phenotype was more virulent following intraperitoneal or intravenous inoculation; however, there was no difference in the incidence of colonization or bacteraemia following intranasal inoculation. Furthermore, organisms colonizing the pharynx of rats had the serum-resistant phenotype. Thus, different phenotypes of the same strain of $H$. influenzae b differed in virulence following parenteral, but not intranasal, inoculation of bacteria. This could be explained by a change from serumsensitive to serum-resistant phenotype shortly after entering the nasopharynx. The phenotype of micro-organisms grown in vitro may differ from organisms in infected individuals and these differences may be of critical importance in studies of immunity to infection and the pathogenesis of infection.
\end{abstract}

\section{INTRODUCTION}

Studies on the virulence of the human pathogen Haemophilus influenzae have been facilitated by the availability of a biologically relevant rat model. In studying virulence, most investigators inoculate suspensions of organisms which are grown in vitro. During in vitro growth, a shift in the phenotype of the organisms may occur (Shaw et al., 1976; Ward et al., 1970). A striking example of phenotypic change has been described for $H$. influenzae type b where organisms from infected rats are relatively resistant to bactericidal activity involving antibodies to somatic antigens compared to the identical strain grown in synthetic media (Shaw et al., 1976). Since brothgrown, serum-sensitive organisms become relatively serum-resistant following 30 min incubation in normal serum, it is evident that this resistance reflects a phenotypic shift rather than selection of genetically distinct, serum-resistant organisms. Anderson et al. (1980) showed that this relative serum resistance involves an altered interaction of serum antibodies with lipopolysaccharide (LPS) determinants; both phenotypes are sensitive to bactericidal activity mediated by anticapsular antibodies. A potential biological relevance of these observations was suggested since limited experiments showed that intra vascular clearance of broth-grown, serumsensitive $H$. influenzae b was greater than that of the same strain which was pre-incubated in serum to induce resistance to somatic antibodies (Shaw et al., 1976). Thus, as previous studies of $H$. influenzae b pathogenesis using the rat model have used broth-grown organisms (Smith et al., 1973; Moxon et al., 1974; Weller et al., 1977; Rubin \& Moxon, 1983; Moxon \& Vaughn 1981),

† Present address : Department of Pediatrics, The Schneider Children's Hospital of Long Island Jewish-Hillside Medical Center, New Hyde Park, NY 11042, USA.

$\ddagger$ Present address: Department of Paediatrics, John Radcliffe Hospital, University of Oxford, Headington, Oxford OX3 9DU, UK. 
these studies may not have accurately simulated the pathogenesis observed following natural infection. In the present studies, we incubated broth-grown serum-sensitive $H$. influenzae b in a dialysate of serum to obtain serum-resistant organisms and we compared the virulence of the serum-sensitive and serum-resistant phenotypes of $H$. influenzae b following systemic and intranasal inoculation of rats.

\section{METHODS}

Organisms, media and growth. One-step streptomycin-resistant $\left(\mathrm{Sm}^{r}\right)$, kasugamycin-resistant $\left(\mathrm{Kg}^{\mathrm{r}}\right)$, or rifampin-resistant ( $\mathrm{Ri}^{r}$ ) mutants of $H$. influenzae b strain Eag were used (Smith et al., 1973). Strain S-2 is a spontaneous capsule-deficient mutant of strain Eagan $\mathrm{Sm}^{r}$ (Weller et al., 1977). Strain Rd is a capsule-deficient $H$. influenzae strain (Alexander \& Leidy, 1951). Broth-grown $\boldsymbol{H}$. influenzae b were grown and prepared for animal inoculation as previously described (Rubin \& Moxon, 1983). For quantification of colony counts, body fluids and appropriate dilutions of the inoculum were cultured on solid media as previously described (Rubin \& Moxon, 1983), with added streptomycin $\left(500 \mu \mathrm{g} \mathrm{ml}^{-1}\right)$, kasugamycin $\left(100 \mu \mathrm{g} \mathrm{ml}^{-1}\right)$, or rifampin $\left(100 \mu \mathrm{g} \mathrm{ml}^{-1}\right)$.

Serum-resistant phenotype, bactericidal assay. Broth-grown, mid-exponential phase cultures of $\boldsymbol{H}$. influenzae b were pelleted, resuspended in buffer or in a low molecular weight dialysate of normal human serum to a bacterial density of $10^{+}$organisms ml-1, and incubated for $30 \mathrm{~min}$ at $37^{\circ} \mathrm{C}$ to obtain bacteria with the serum-sensitive or serum-resistant phenotype, respectively (Anderson et al., 1980). Serum resistance was assessed in a serum bactericidal assay. Organisms $(200 \mu \mathrm{l})$ were incubated at $37^{\circ} \mathrm{C}$ in $20 \%$ immune serum $(50 \mu \mathrm{l})$. (The immune serum, containing a high proportion of anti-LPS antibodies but lacking anti-capsular antibody, was obtained from rats previously inoculated with $H$. influenzae strain $R d$ and stored at $-70^{\circ} \mathrm{C}$ to preserve complement activity.) Samples $(10 \mu 1)$ were quantitatively cultured initially and following a 20 or 30 min incubation. There was generally either a $<10 \%$ or $>70 \%$ decrease in the colony counts following incubation. Organisms were considered serumsensitive if there was a $>50 \%$ decline in colony counts during the 20 or $30 \mathrm{~min}$ incubation. Serum was defined as having bactericidal activity if there was a $>50 \%$ decline in viable counts of broth-grown $\mathrm{H}$. influenzae b following a 20 min incubation.

Animals. Sprague-Dawley rats strain COBS (obtained from Charles River Laboratories, Wilmington, Mass., USA) were used in all experiments.

Intravenous inoculation studies. To induce serum antibodies to LPS, 5-d-old rats were inoculated intranasally with $10^{7}$ capsule-deficient $H$. influenzae strain S-2. Bactericidal activity of serum was confirmed using serum taken at $38 \mathrm{~d}$. At $40 \mathrm{~d}$ old these rats were inoculated intravenously with approximately 1000 serum-resistant or serumsensitive $H$. influenzae b via a lateral tail vein after light ether anaesthesia. Rats of this age are highly susceptible to bacteraemia following intravenous inoculation with $H$. influenzae $b$. At varying intervals after inoculation, a single blood sample was obtained by heart puncture from groups of three or four animals and quantitatively cultured on solid media (limit of detection 10 organisms $\mathrm{ml}^{-1}$ ).

Intraperitoneal inoculation studies. Unanaesthetized 14-d-old rats were inoculated intraperitoneally with $10^{4}$ organisms of either the serum-sensitive or serum-resistant phenotype. Blood $(10 \mu \mathrm{l})$ was obtained for culture following tail vein puncture at $24 \mathrm{~h}$. Animals were observed for death occurring within $7 \mathrm{~d}$ of inoculation.

Intranasal inoculation studies. Rats $20 \mathrm{~d}$ old, previously shown to be highly susceptible to $H$. influenzae b colonization and bacteraemia following intranasal inoculation (Rubin \& Moxon, 1983), were housed in separate cages to avoid intralitter spread of $H$. influenzae b (Halsey et al., 1980) and were intranasally inoculated $(25 \mu \mathrm{l}$ sample containing varying numbers of organisms) as previously described (Moxon \& Vaughn, 1981). Pharyngeal secretions were obtained for culture or as a source of organisms for the bactericidal assay as previously described (Rubin \& Moxon, 1983). Blood was obtained for culture $(25 \mu 1)$ or use in a bactericidal assay following tail vein puncture.

\section{RESULTS}

\section{Bacteraemia following intravenous inoculation of serum-sensitive or serum-resistant $H$. influenzae $b$}

Blood cultures were obtained $5 \mathrm{~min}$ to $24 \mathrm{~h}$ following intravenous inoculation with serumsensitive or serum-resistant $H$. influenzae b. Combining all time points sampled, there was a higher magnitude of bacteraemia in rats inoculated with serum-resistant organisms than in those inoculated with serum-sensitive $H$. influenzae b $(P<0.05$, Wilcox 2-sample rank sum test, 2 -tailed) (Fig 1). At 1 and $3 \mathrm{~h}$ after inoculation, there was a significantly higher magnitude of bacteraemia in rats inoculated with serum-resistant $H$. influenzae $b$ than in those inoculated with serum-sensitive organisms $\left[95 \%\right.$ confidence intervals of $\log _{10}$ geometric mean bacteria per $\mathrm{ml}$ blood: $(2 \cdot 71,2 \cdot 99)$ vs $(1 \cdot 06,2 \cdot 10)$ at $1 \mathrm{~h}$ and $(3 \cdot 15,3 \cdot 55)$ vs $(1 \cdot 72,2 \cdot 36)$ at $3 \mathrm{~h}$ ]. 


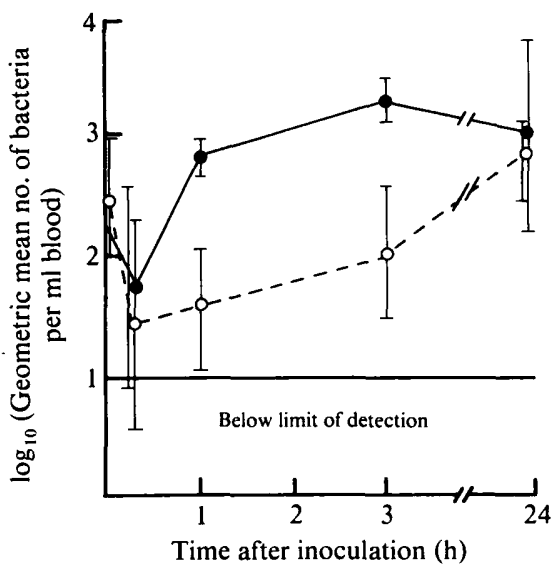

Fig. 1. Bacteraemia following intravenous inoculation of 40 -d-old rats with $10^{3}$ serum-sensitive $(O)$ or serum-resistant (O) $H$. influenzae b. Each point represents the geometric mean magnitude of bacteraemia for three or four rats; blood was obtained for culture once for each rat. Bars represent one SD of the mean. Rats had been intranasally inoculated at $5 \mathrm{~d}$ of age with $10^{7} \mathrm{H}$. influenzae $\mathrm{b}$ to ensure the presence of serum bactericidal antibodies to L.PS.

\section{Bacteraemia and mortality following intraperitoneal inoculation of serum-sensitive or serum-resistant $H$. influenzae $b$}

To compare further the virulence of the serum-sensitive and serum-resistant phenotypes of $H$. influenzae b, 14-d-old rats were inoculated intraperitoneally with $10^{4}$ organisms of one or the other phenotype. All animals developed bacteraemia; there was a significantly greater mortality after inoculation with the serum-resistant phenotype (16/19) than after inoculation with the serum-sensitive phenotype $(8 / 18)\left(P<0.05, \chi^{2}\right)$. Thus, a difference in virulence of the two phenotypes could be demonstrated following systemic administration of organisms.

\section{Phenotype of $H$. influenzae $b$ colonizing the pharynx}

Since infection in humans is initiated in the nasopharynx, the relevance of these observed differences in virulence following systemic inoculation of organisms was uncertain. Therefore, we studied the phenotype of organisms colonizing the nasopharyn $x$ and compared colonization and bacteraemia following intranasal inoculation with the serum-sensitive or serum-resistant phenotype of $H$. influenzae b.

Pharyngeal secretions were obtained from nine colonized rats (from six different litters) 5 to $7 \mathrm{~d}$ after intranasal inoculation with approximately $10^{4} \mathrm{H}$. influenzae b at age $20 \mathrm{~d}$. Serial 10 -fold dilutions of these secretions were assayed in a serum bactericidal assay (see Methods). $H$. influenzae $b$ in secretions survived the $30 \mathrm{~min}$ incubation in comparison to the survival of brothgrown organisms (Table 1). Thus, $H$. influenzae b colonizing the pharynx were of the serumresistant phenotype. Furthermore, when broth-grown organisms were pre-incubated with filter sterilized pharyngeal washes, there was a higher percentage survival in the bactericidal assay (mean 19\%,n $=5$ ) as compared to organisms pre-incubated with buffer (percentage survival $2 \%$ ). Although the mean percentage survival was lower than that for bacteria which had been pre-incubated with dialysate $(117 \%)$, this nevertheless indicated that a factor(s) necessary for induction of serum resistance is present in pharyngeal secretions.

Colonization efficiency of serum-sensitive and serum-resistant phenotypes of $H$. influenzae $b$

To maximize the chances of detecting differences in colonization efficiency between the two phenotypes, an inoculum size representing the $\operatorname{ID}_{50}$ for colonization $\left(10^{2}-10^{3}\right.$ organisms) was used. There was no difference in the incidence of colonization following intranasal inoculation with either the serum-sensitive or serum-resistant phenotype of $H$. influenzae b (Table $2 a$ ). 
Table 1. Survival of $H$. influenzae $b$ from pharyngeal washes and broth-grown culture in a serum bactericidal test

20-d-old rats were inoculated intranasally with approximately $10^{4} \mathrm{H}$. influenzae b; pharyngeal washes were obtained 5 to $6 \mathrm{~d}$ later. Organisms from both sources were tested in a serum bactericidal assay (see text). (Percentage survival of greater than 100 indicates a net replication of organisms during the 20 or $30 \mathrm{~min}$ incubation).

\section{Source of $\boldsymbol{H}$. influenzae b}

Expt no. 1 Pharyngeal washes $(n=5)$ Broth-grown culture $(n=2)$

Expt no. 2 Pharyngeal washes $(n=4)$ Broth-grown culture $(n=1)$ Broth-grown incubated with dialysate $(n=1)$
Mean percentage survival

0

113

Table 2. Nasopharyngeal colonization after intranasal inoculation with serum-sensitive and/or serum-resistant $H$. influenzae $b$

\begin{abstract}
20-d-old rats were inoculated intranasally with approximately $10^{3}$ organisms; colonization was assessed by obtaining pharyngeal washes after $48-72 \mathrm{~h}$ which were cultured on solidified media made selective with the appropriate antibiotic. (a) Incidence of colonization following intranasal inoculation of rats with either serum-sensitive or serum-resistant $\boldsymbol{H}$. influenzae $\boldsymbol{b}$. Data represent combined results of two separate experiments. (b) Incidence of colonization following intranasal inoculation of rats with an approximately equal mixture of serum-sensitive and serum-resistant $H$. influenzae b. These two phenotypes were distinguished by using two different antibiotic-resistant variants of the same $H$. influenzae b strain which had similar colonization efficiency. Data represent combined results of three separate experiments in which a total of 40 rats were inoculated.
\end{abstract}

\title{
No. colonized/
} no. inoculated*

(a) Phenotype inoculated

$\begin{array}{ll}\text { Serum-sensitive } & 10 / 35(31) \\ \text { Serum-resistant } & 11 / 35(29) \\ \text { (b) Phenotype recovered } & \\ \text { Either } & 30 / 40(75) \\ \text { Serum-sensitive } & 15 / 40(38) \dagger \\ \text { Serum-resistant } & 19 / 40(48) \dagger\end{array}$

* Percentages given in parentheses.

$\dagger P>0 \cdot 25\left(\chi^{2}\right)$.

To compare further the colonization efficiency, individual rats were inoculated with a mixture of serum-sensitive and serum-resistant $\boldsymbol{H}$. influenzae b (with two different antibiotic-resistant markers $-\mathrm{Sm}^{\mathrm{r}}$ or $\mathrm{Ri}^{\mathrm{r}}$, see Methods) allowing the serum-sensitive and serum-resistant phenotypes to compete within the same animal, thereby allowing each animal to serve as its own control. There was no significant difference in the incidence of colonization after inoculation with the serum-sensitive and serum-resistant phenotypes of $H$. influenzae b (Table $2 b$ ). Parallel experiments compared the colonization efficiency of the two antibiotic-resistant variants of $H$. influenzae b by inoculating rats with a mixture of $\mathrm{Sm}^{\mathrm{r}}$ and $\mathrm{Ri}^{\mathrm{r}}$ variants of serum-sensitive $H$. influenzae b. The two antibiotic-resistant variants colonized the nasopharynx of rats with approximately equal efficiency (L. G. Rubin \& E. R. Moxon, unpublished observation) and thus differences in colonization between these two antibiotic-resistant variants were unlikely to confound the interpretation of this experiment. Thus, serum sensitivity does not appear to be a critical determinant of initial pharyngeal survival and subsequent pharyngeal colonization.

\section{Bacteraemia after intranasal inoculation with serum-resistant or serum-sensitive $H$. influenzae $b$}

To maximize the chances of detecting differences in the incidence or magnitude of bacteraemia following intranasal inoculation, an inoculum $\left(10^{3}-10^{4}\right.$ organisms) was chosen which would result in a 50-100\% incidence of bacteraemia. In order to maximize the chances of detecting differences between the two phenotypes, only rats whose serum (obtained $2 \mathrm{~d}$ before 
Table 3. Bacteraemia after intranasal inoculation with serum-sensitive and serum-resistant H. influenzae $b$

The incidence and magnitude of bacteraemia after intranasal inoculation of 20 - $d$-old rats with an approximately equal mixture (approximately 3000 organisms) of serum-sensitive and serum-resistant $H$. influenzae b was measured. The two phenotypes were distinguished by using two different antibioticresistant variants of the same $H$. influenzae b strain which were of similar virulence. Blood $(25 \mu l)$ was obtained $72 \mathrm{~h}$ after inoculation and was cultured on solidified media made selective with the appropriate antibiotic. The $95 \%$ confidence intervals are given in parentheses.

$\begin{array}{lcc}\text { Phenotype recovered } & \begin{array}{c}\text { No. bacteraemia/ } \\ \text { no. inoculated }\end{array} & \begin{array}{c}\text { Geometric mean bacteria } \\ \text { per ml blood }\end{array} \\ \text { Either } & 14 / 18 & - \\ \text { Serum-sensitive } & 11 / 18 & 2 \cdot 48(1 \cdot 95,3 \cdot 01) \\ \text { Serum-resistant } & 11 / 18 & 2 \cdot 36(1 \cdot 88,2 \cdot 84)\end{array}$

inoculation) had bactericidal activity against $H$. influenzae b (see Methods) were used in this experiment. Following inoculation with an approximately equal mixture of serum-sensitive and serum-resistant $\boldsymbol{H}$. influenzae b (using $\mathrm{Sm}^{\mathrm{r}}$ and $\mathrm{Kg}^{\mathrm{r}}$ variants for antibiotic-resistant markers), there was no significant difference in the incidence or magnitude of bacteraemia after inoculation of organisms originally of the serum-sensitive or serum-resistant phenotype (Table 3). Parallel experiments compared the bacteraemia following intranasal inoculation with the $\mathrm{Sm}^{r}$ and $\mathrm{Kg}^{r}$ variants of serum-sensitive $H$. influenzae $\mathrm{b}$. The incidence and magnitude of bacteraemia with these two antibiotic-resistant mutants, possessing similar virulence properties, were similar (L. G. Rubin \& E. R. Moxon, unpublished observation). Thus, inoculation with either the serum-sensitive or serum-resistant phenotype of $H$. influenzae $\mathrm{b}$ resulted in a similar incidence and magnitude of bacteraemia.

\section{DISCUSSION}

The serum-resistant phenotype was more virulent following intravenous or intraperitoneal inoculation than the serum-sensitive phenotype. However, since infection is initiated via the nasopharynx, the biological relevance of these observations to infection was uncertain. Following intranasal challenge with an inoculum containing the $\mathrm{ID}_{50}$ for colonization or bacteraemia, there was no difference between the two phenotypes in the incidence of colonization or bacteraemia, respectively. Furthermore, we showed that organisms colonizing the pharynx of rats have the serum-resistant phenotype. The factor(s) necessary for expression of the serum-resistant phenotype must be present in the nasopharynx as organisms must have acquired this phenotype in the nasopharyngeal environment. If this phenotypic shift had occurred shortly after inoculation, thereby rapidly eradicating any differences in serum-sensitivity between the two inocula, this would provide an explanation for the similar colonization and bacteraemia observed after inoculation with the two phenotypes. The efficient colonization observed following inoculation with a small number of serum-sensitive organisms implies that bactericidal activity involving anti-LPS antibodies may not be an important host defence against $\boldsymbol{H}$. influenzae b colonization and/or organisms inoculated into the nasal cavity acquire serum resistance very shortly after inoculation.

Only one strain of $H$. influenzae b was used in these studies. Strain Eag was chosen because it has been used in many of the experimental studies of $H$. influenzae pathogenesis (Smith et al., 1973; Moxon et al., 1974; Rubin \& Moxon, 1983; Alexander \& Leidy, 1951). However, the results may be applicable to most type b strains as Anderson et al. (1980) found that all eight type b strains tested underwent a phenotypic shift to relative serum resistance. The age of rats chosen for the study of comparative virulence varied with the route of inoculation (i.e. 40-d-old rats for intravenous inoculation, 14-d-old rats for intraperitoneal inoculation, 20-d-old rats for intranasal inoculation). These particular ages were chosen for the reproducibility with which rats could be infected by the particular route. However, since intravenous or intraperitoneal inoculation results in bacteraemia in rats aged 14,20 or $40 \mathrm{~d}$ and intranasal inoculation results in colonization and bacteraemia in rats aged 14 or $20 \mathrm{~d}$, it is unlikely that the use of rats of other ages would have altered the results. 
Differences in serum sensitivity between organisms from infected hosts and organisms grown in vitro have also been demonstrated for Neisseria gonorrhoeae. Although strains from disseminated infection may retain their resistance to serum on subculture and thus represent genetically stable, serum-resistant organisms, isolates from mucosal sites may lose their resistance upon subculture and regain phenotypic resistance to killing by human serum following incubation in genital secretions (Martin et al., 1982). Thus, in vitro-grown $N$. gonorrhoeae may undergo a phenotypic shift to relative serum resistance similar to $H$. influenzae (Ward et al., 1970). Although urethral exudates from infected individuals tend to infect volunteers more readily than in vitro-grown organisms (Hill, 1943), the lack of a biologically relevant animal model for this organism has hampered attempts to compare the virulence of the serum-sensitive and serum-resistant phenotypes in a controlled fashion.

In studying immunity to bacterial infections and the pathogenesis of bacterial infections, the phenotype of the organisms may be of critical importance to virulence and the phenotype of organisms grown on artificial media may differ in important ways from the phenotype of the organisms in the infected host.

This work was supported in part by Training Grant no. 1T32 AI07195 (National Institutes of Health) and by the Board of the Hospital for Consumptives of Maryland (Eudowood). E. R. M. was a recipient of Research Career Development Award no. 5K04 AI00300 (National Institutes of Allergy and Infectious Diseases). We thank Porter Anderson for his critical view of the manuscript and Ann Lemke and Kathy Haynes for their assistance in preparation of the manuscript.

\section{REFERENCES}

Alexander, H. E. \& LeIDY, G. (1951). Determination of inherited traits of Haemophilus influenzae by desoxyribonucleic acid fractions isolated from typespecific cells. Journal of Experimental Medicine 93, 345-351.

Anderson, P., Flesher, A., Shaw, S., Harding, A. L. \& SMITH, D. H. (1980). Phenotypic and genetic variation in the susceptibility of Haemophilus influenzae type $b$ to antibodies to somatic antigens. Journal of Clinical Investigation 65, 885-891.

Halsey, N. A., Koroch, C., Johansen, T. L. \& Glode, M. P. (1980). Intralitter transmission of Haemophilus influenzae type $\mathrm{b}$ in infant rats and rifampin eradication of nasopharyngeal colonization. Journal of Infectious Diseases 142, 739-743.

Hill, J. (1943). Experimental infection with Neisseria gonorrhea. I. Human inoculations. American Journal of Syphilis, Gonorrhea and Venereal Diseases 27, 733771 .

Martin, P. M. V., Patel, P. V., Parsons, N. J. \& SMITH, H. (1982). Induction of gonococci of phenotypic resistance to killing by human serum by human genital secretions. British Journal of Venereal Diseases 58, 363-365.

Moxon, E. R. \& Vaughn, K. A. (1981). The type b capsular polysaccharide as a virulence determinant of Haemophilus influenzae: studies using clinical isolates and laboratory transformants. Journal of Infectious Diseases 143, 517-524.

Moxon, E. R., Smith, A. L., Averil., D. R. \& Smith, D. H. (1974). Haemophilus influenzae meningitis in infant rats after intranasal inoculation. Journal of Infectious Diseases 129, 154-162.

Rubin, L. G. \& Moxon, E. R. (1983). Pathogenesis of bloodstream invasion with Haemophilus influenzae type b. Infection and Immunity 41, 280-284.

Shaw, S., Smith, A. L., Anderson, P. \& Smith, D. H. (1976). The paradox of Haemophilus influenzae type b bacteremia in the presence of serum bactericidal activity. Journal of Clinical Investigation 58, 10191029.

Smith, A. L., Smith, D. H., Averill, D. R., Marino, J. \& Moxon, E. (1973). Production of Haemophilus influenzae type $b$ meningitis in infant rats by intraperitoneal inoculation. Infection and Immunity 8, 278-290.

Ward, M. E., Watt, P. J. \& GlynN, A. A. (1970). Gonococci in urethral exudates possess a virulence factor lost on subculture. Nature, London 227, 382384.

Weller, P. F., Smith, A. L., Anderson, P. \& Smith, D. H. (1977). The role of encapsulation and host age in the clearance of Haemophilus influenzae bacteremia. Journal of Infectious Diseases 135, 34-41. 